\title{
MA-XRF imaging on René Magritte's La condition humaine: insights into the artist's palette and technique and the discovery of a third quarter of La pose enchantée
}

\author{
Alice Tavares da Silva ${ }^{1 *} \mathbb{D}$, Stijn Legrand ${ }^{2}$, Geert Van der Snickt ${ }^{2,3}$, Rupert Featherstone ${ }^{1}$, Koen Janssens ${ }^{2}$ \\ and Giorgia Bottinelli ${ }^{4}$
}

\begin{abstract}
Magritte's composition La condition humaine, 1935 was found to conceal under its paint layers an entire quarter of a lost composition by the artist, until recently only known from a small black/white catalogue illustration - La pose enchantée, 1927. This study is the latest contribution to the discovery of the artist's missing painting, now known to have been cut into four parts and re-used by Magritte as the support for new compositions. Non-destructive analytical and examination methods and specifically macroscopic X-ray fluorescence (MAXRF) scanning and conventional $X$-ray radiography (XRR) were the two non-destructive analytical and examination methods used to study both compositions and add to the existing knowledge on the artist's palette during both periods. The first method is capable of identifying the presence and the distribution of key chemical elements present in artists' materials. In some instances elemental mapping provided useful information on the hidden painting, but conventional X-ray radiography (XRR) enabled a better visualisation of the form and paint application of the underlying composition. Furthermore, the turnover edges of the canvas reveal after over 80 years the artist's palette directly to the viewer. Additional XRF scanning of this exposed paint has confirmed and added to the existing research published to date of this lost painting, including a proposed colour reconstruction, but at the same time highlighting the need for further analytical research involving both non-destructive point analysis and the use of paint samples.
\end{abstract}

Keywords: René Magritte, La condition humaine, La pose enchantée, Macroscopic X-ray fluorescence, MA-XRF scanning, Hidden painting

\section{Introduction}

The painting La condition humaine $(1935,54.2 \times 73.2 \times$ $1.6 \mathrm{~cm}$, René Magritte Catalogue Raisonné [RMCR] no. 390), shown in Fig. 1 is by the Belgian surrealist artist René Magritte (1898-1967).

It is one of four variants entitled La condition humaine that Magritte painted between 1933 and 1935 (RMCR no. 351, 372 and 387) [1]. It depicts a painting within a painting, a favourite recurring theme used by the artist

\footnotetext{
*Correspondence: at225@cam.ac.uk

1 Hamilton Kerr Institute, University of Cambridge,

Cambridge CB22 4NE, UK

Full list of author information is available at the end of the article
}

throughout his oeuvre. In this version Magritte depicts the inside of a cave. There is a fire in the left corner conveying a warm glow to the foreground while the cave provides a view over a distant mountainous landscape. A painted canvas standing on an easel and placed at the opening of the cave, depicts the continuation of this landscape but also contains a castle perched on a precipice.

The painting has been in the collection of the Norwich Castle Museum since 1995 when it was accessioned as part of a large bequest of 20th century art known as the Adeane Collection. Robert Adeane acquired the painting in 1966 from the Mayor Gallery in London, and its 


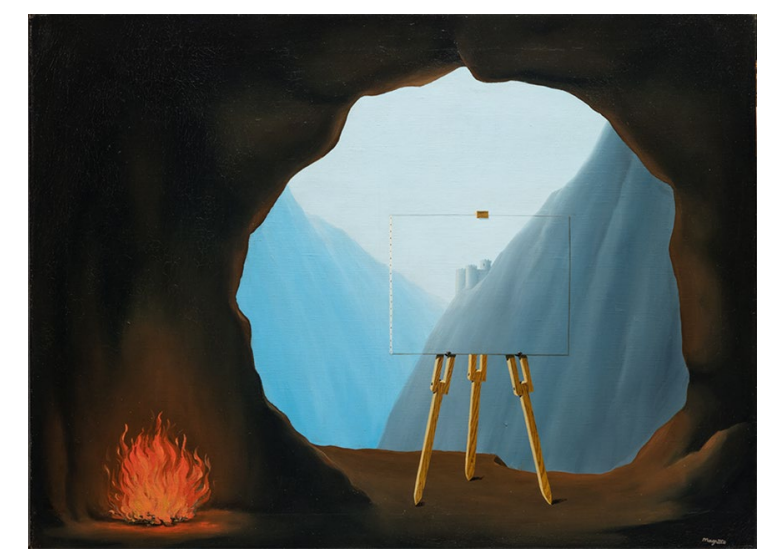

Fig. 1 René Magritte, La condition humaine (The Human Condition, 1935). Oil on canvas, $54.2 \times 73.2 \times 1.6 \mathrm{~cm}$. ${ }^{\circledR}$ Norfolk Museums Service

provenance can be traced back to Basil Wright, London, 1936 [1].

In February 2016, the painting underwent a routine examination following the request for loan to the exhibition La trahison des images, at the Pompidou Centre/ Paris, (September 2016 to January 2017). At this point conservators noticed that the turnover edges of the canvas extended onto the reverse and were painted with a scheme that did not correspond to the composition on the front (Fig. 2a).

Magritte had clearly re-used an older canvas to paint this version of La condition humaine.

The re-use of earlier unwanted paintings by artists is well known to art specialists. Moreover, there are well documented examples of Magritte himself undertaking such practices. ${ }^{1}$

However, whilst noting this as an interesting find, a closer inspection of the edges of the painting revealed a much more exciting connection. In this case, the colours exposed seemed to relate to a recently discovered painting by the artist, La pose enchantée, dating from 1927, illustrated in the Catalogue Raisonné (RMCR no. 163), of which the whereabouts have been unknown since 1932 [2] (Fig. 2).

In 2013, a quarter of Magritte's La pose enchantée was discovered below another painting by the artist in the

\footnotetext{
${ }^{1}$ Examples include:

The Song of the Storm, 1938, RMCR no. 448 painted over an earlier portrait.

The Secret Landscape, 1935, RMCR no. 367, painted over part of an earlier composition entitled The Unknown Role, 1928.

Time Transfixed, 1938, painted over an abandoned composition entitled Spring Eternal, for which there are two study drawings dating from 193738. Report by Allison Langley Art Institute of Chicago, 2013. https://www. youtube.com $/$ watch? $v=$ FLDIQbDcP7E\&sns $=e m$.
}

collection of the Museum of Modern Art (MoMA), NY [3]. During preparations for the exhibition "Magritte: The Mystery of the Ordinary, 1926-1938", 2014, it became clear that Le Portrait 1935, concealed the top left quarter of the lost composition. Moreover, the same team of conservators and curators led by Michael Duffy was fortunate to discover the bottom left quarter of $L a$ pose enchantée, when examining Le modèle rouge, 1935 (RMCR no. 382, Moderna Museet, Stockholm, Sweden), then an incoming loan to the same exhibition. At that point, the left half of the lost composition had been discovered [4]. In the next few paragraphs, we will discuss how in 2016, three years after the initial discovery, the whereabouts of the lower right section of this lost composition became known.

\section{Experimental}

Chemical element mapping was performed on the painting using a Macroscopic X-ray fluorescence (MA-XRF) scanning instrument, built by the University of Antwerp. This device is an advanced version of the ' $\mathrm{B}$ ' setup described by Alfeld et al. [5]. A measuring head is moved over the paint surface by two X-Y motors (Newport, USA) with a distance of ca $8 \mathrm{~mm}$ between the detector snout and paint surface. The measuring head consists of a $10 \mathrm{~W}$ Rh target X-ray tube (Moxtek, USA) and a SDD detector (Vortex EX90, USA) with an energy resolution of $<145 \mathrm{eV}$ at $\mathrm{Mn}-\mathrm{K}_{\alpha}$. The incident primary beam is at a right angle to the paint surface, while the detector is positioned at a $50^{\circ}$ angle with respect to the incident beam. The beam size is defined by means of a lead collimator with a pinhole diameter of $0.8 \mathrm{~mm}$. For the Magritte painting, elemental distribution maps were collected over an area measuring $54.2 \times 73.2 \mathrm{~cm}^{2}$, with a step size of $750 \mu \mathrm{m}$ and a dwell time of $200 \mathrm{~ms} / \mathrm{step}$; X-ray tube settings were $45 \mathrm{kV}$ and $200 \mu \mathrm{A}$. The ensuing data cube was processed with in-house developed Datamuncher software [6] and the X-ray spectrometry software packages PyMcA [7] and bAxil [8].

The result of the scanning and fitting operation are two dimensional distribution images, one for each fitted elemental line. In these images a brighter pixel means a higher fitted XRF intensity in that pixel. Despite the fact that X-rays possess more penetrative power than most other types of radiation used for imaging purposes, these are prone to absorption phenomena as well. Especially the lower energetic XRF signals (which are at the border with the extreme UV-band), are more sensitive to absorption effects.

Also the layer build-up has an influence on the distribution images, as heavier elements absorb XRF radiation better than lighter elements. As a result, it is possible to see heavier elements, overpainted by lighter elements, 


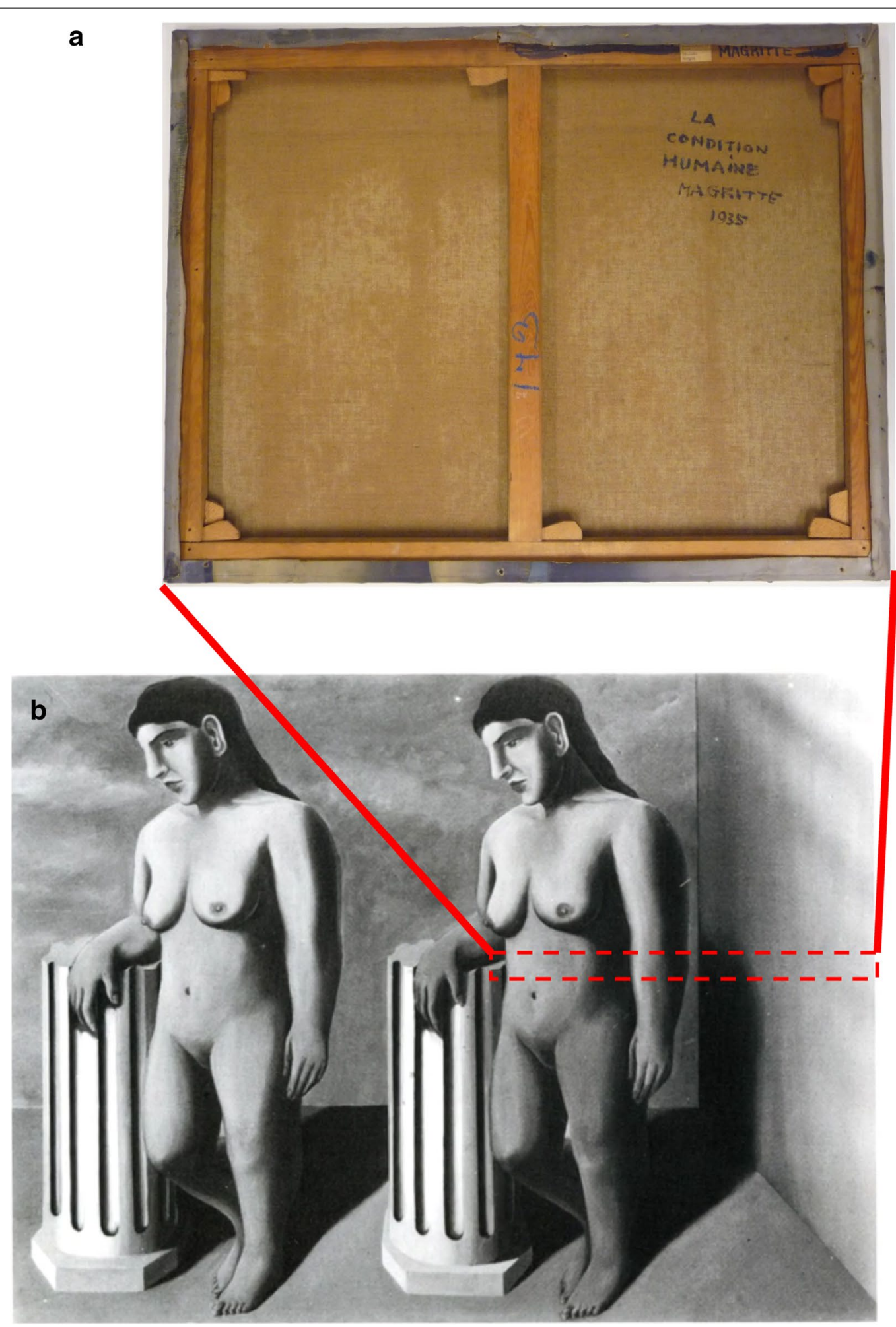

Fig. 2 a Reverse of La condition humaine (surface composition) ${ }^{\oplus}$ Norfolk Museums Service, b René Magritte, La pose enchantée, (The Enchanted Pose, 1927) B/W illustration from the Catalogue Raisonné (red dotted line showing area corresponding to the paint found on the turnover edges of La condition humaine) 
whereas it is not possible to see lighter elements overpainted by heavier elements (e.g. lead). A clear example is the column of the original composition: the bright areas, where lead white was applied to create highlights, the $\mathrm{XRF}$-signals from the underlying $\mathrm{Zn}$-layer are absorbed to a greater extent than those originating from under the shadow regions (which are painted using pigments consisting of lighter elements).

\section{Results and discussion}

As mentioned earlier, La condition humaine 1935, is painted over a quarter of La pose enchantée 1927, in a similar way to Le portrait and Le modèle rouge. Together with a matching date of 1935 and close dimensions to the latter paintings, La condition humaine exposed enough colour and compositional features on its edges to positively link it to the missing painting as illustrated in Fig. 2.

It was possible at this stage to visually relate the exposed paint to elements from the missing composition La pose enchantée and determine which part was actually concealed under the current painting.

The painting was subsequently examined with X-ray radiography (XRR) which confirmed this finding (Fig. 3).

When rotated $180^{\circ}$, the lower torso, the hand and the legs of the standing figure can be easily distinguished in the XRR image. A direct correlation with the lower right quarter of La pose enchantée can be made, as illustrated in Fig. 4. Other features such as part of the column and the shadow that the figure casts on the foreground and wall can also be seen in the rotated X-ray radiograph. The previously discovered quarters of the painting were rotated over $90^{\circ}$ before repainting.

Following from the studies and research already carried out on Le portrait and Le modèle rouge, the painting

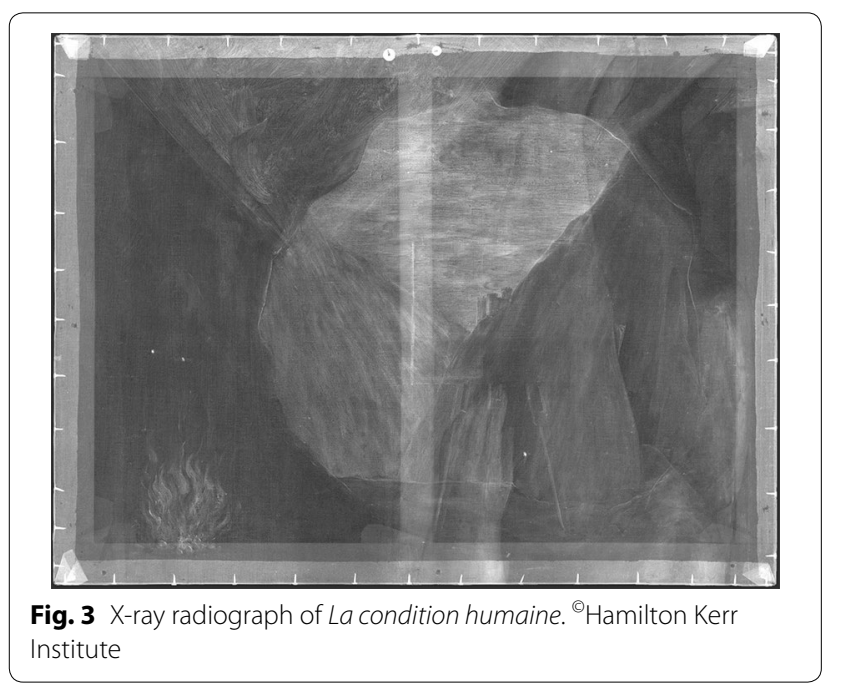

underwent further examinations with MA-XRF analytical and imaging techniques, employed to collect a set of elemental distribution maps of the painting. The ensuing series of maps provided confirmation and further information on the palette and techniques used by Magritte whilst painting La pose enchantée and La condition humaine.

\section{The hidden painting: La pose enchantée}

The series of elemental maps resulting from a full MAXRF scan of the painting can be seen in Fig. 5.

Distinct features from the underlying La pose enchantée as well as compositional elements from the upper painting, are revealed in both the lead $(\mathrm{Pb})$ and zinc ( $\mathrm{Zn})$ maps. This indicates the presence of both of these elements in both compositions and concurs with the proposed layer build-up of Le portrait, that the earliest composition was painted on top of a double preparation with a thin lead-based priming over a zinc based ground layer [9]. In fact, the zinc distribution map shows an emphasized canvas weave pattern, corroborating that a pigment rich in this element was applied directly to the canvas. As in the case of the Le Portrait, the zinc maps appear as a negative image of the lead distribution, an indication that the $\mathrm{Zn}$ signal is blocked locally by the application on top of it of lead rich paint used as a priming and in the modelling of the nude figure of the hidden painting. The fact that the distribution maps of these two elements is complementary is an indication that these elements are present in distinct layers, one on top of another. Furthermore, measurements of the XRF signal taken from the verso side of the canvas show an increase in the intensity of the signal for these two elements, and in addition the zinc is detected relatively more compared to lead, supporting the assumption that the ground build-up is similar to previous cases where sampling was performed; A zinc ( $\mathrm{Zn}$ ) containing ground (where also calcium $-\mathrm{Ca}$ is present), covered by a thinner lead $(\mathrm{Pb})-$ rich ground.

Chromium $(\mathrm{Cr})$ is the only other element that shows some form of detail from the underlying composition. There is a positive signal in the area corresponding to the fraction of sky paint between the arm of the standing figure and the wall, and this can be seen at the centre along the lower edge. The other detected elements are associated with the upper painting, La condition humaine.

The underlying composition clearly visible in the zinc $(\mathrm{Zn})$ and lead $(\mathrm{Pb})$ distribution maps is not easily visible in the distributions for other elements present such as calcium $(\mathrm{Ca})$ and iron $(\mathrm{Fe})$. The explanation for this is that the Zn-rich ground-layer being much thicker than the actual paint layer of this composition means that the primary X-rays 'meet' Zn-atoms over a longer path 

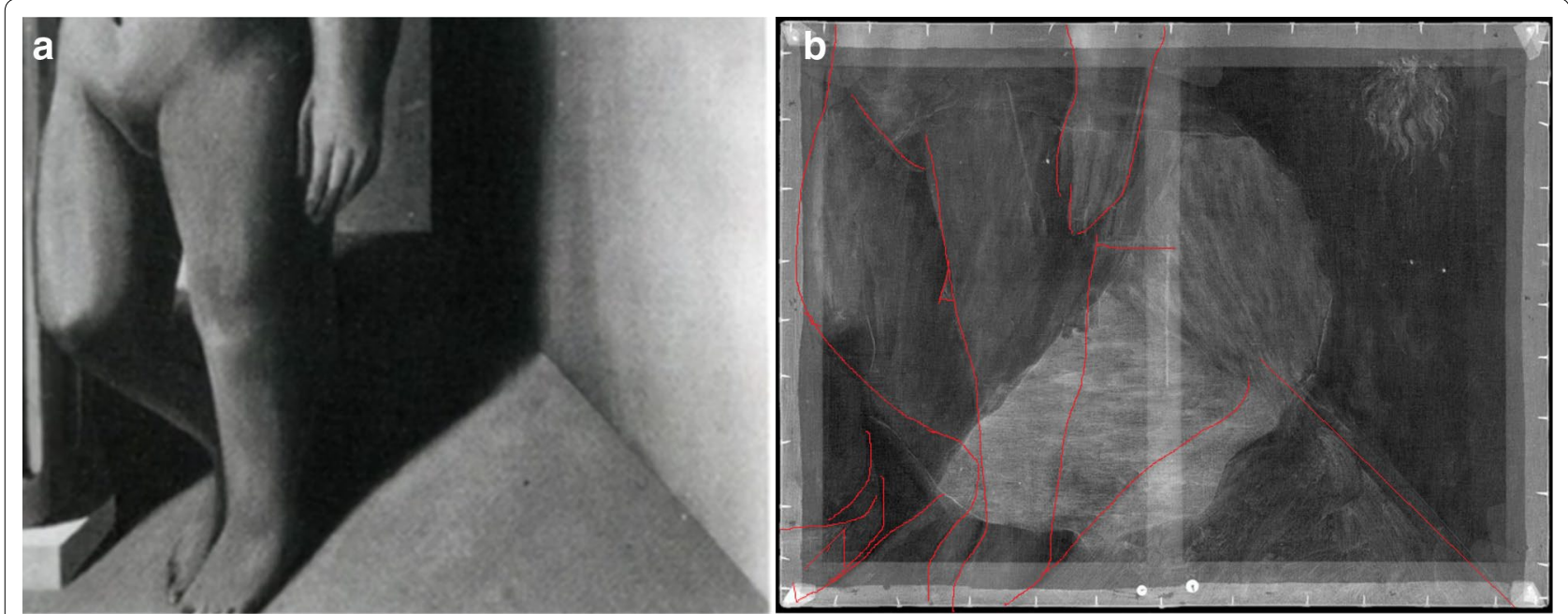

Fig. 4 a La pose enchantée-detail of lower right quarter. $\mathbf{b}$ X-ray radiograph of La condition humaine rotated $180^{\circ}{ }^{\circ}$ Hamilton Kerr Institute. The features of the underlying painting are highlighted in red

length, resulting in a larger number of $\mathrm{Zn}$ atoms emitting their XRF signals. Also, $\mathrm{Zn}$ has a higher atomic number and thus results in more energetic XRF-signals, that are subsequently lesser absorbed when compared to the calcium or the iron signals.

\section{The surface painting: La condition humaine}

The main individual forms of the surface painting such as the cave, the mountains, the fire, the easel and the canvas, can be easily identified in the elemental distribution images. These features are revealed differently in each of the maps reflecting their specific chemical composition as a direct result of the artist's choice of pigments and paint application sequence. As such, a careful study of the elemental maps allows one to deduce information on the composition and build-up of the painted image.

\section{Initial layout of the composition}

The iron ( $\mathrm{Fe}$ ) distribution map shows that Magritte used iron rich pigments to establish the initial general form of the cave. Umbers, ochres and siennas all contain different forms of iron oxide [10,11]. In addition, the distribution of manganese $(\mathrm{Mn})$, although a weaker signal, is very similar to that of iron $(\mathrm{Fe})$ in many areas. This co-location of the two elements suggests the presence of umber ( $\mathrm{Fe}$ and Mn oxides), which occurs in a variety of mid-brown shades.

The lead $(\mathrm{Pb})$ distribution map also shows clearly an initial laying out of the opening of the cave done in a lead-rich paint, probably lead white. This is likely to have been executed in tandem with the first design of the cave walls described here. These observations (as well as the absence of any evidence around the edges of the canvas of an intermediate paint layer) contribute to the deduction that Magritte painted directly onto the underlying composition, without applying an intermediate preparation layer. These initial broad volumes in earth pigments and lead white would have facilitated the painting process significantly by blocking out the underlying composition.

The cave opening displays a fuzzy and irregular edge visible in the XRR image and in the lead distribution map. This is the result of a quick and rough laying out of this initial lead-based form. The edges were later sharpened up by precise application of a fine line of the same mid-brown paint used for the cave, and the pale blue used for the sky. This corrective contour containing iron $(\mathrm{Fe})$ and also to some extent calcium (Ca) and cobalt (Co), appears in the lead $(\mathrm{Pb})$ map as a fine dark outline. This line in negative corresponds to the presence of iron, calcium and cobalt at the surface of the painting, thus masking the lead emission signal coming from the underlying thin lead white layer. These same outlines are visible in the distribution maps for these elements $(\mathrm{Fe}, \mathrm{Co}, \mathrm{Ca})$ as highlights.

\section{Build-up of composition and detail}

Once the layout of the cave with its opening onto a landscape was set, Magritte would have concentrated on giving these areas some extra form and detail. The modelling in the browns of the cave wall seems to be obtained by a mixture of iron, cobalt and calcium. The source of calcium is difficult to pinpoint as it can be due to a number of materials. However the calcium (Ca) signal seems to intensify in the darker shades. As with other known cases (Van der Snickt et al. [9]) Magritte seems to have used 


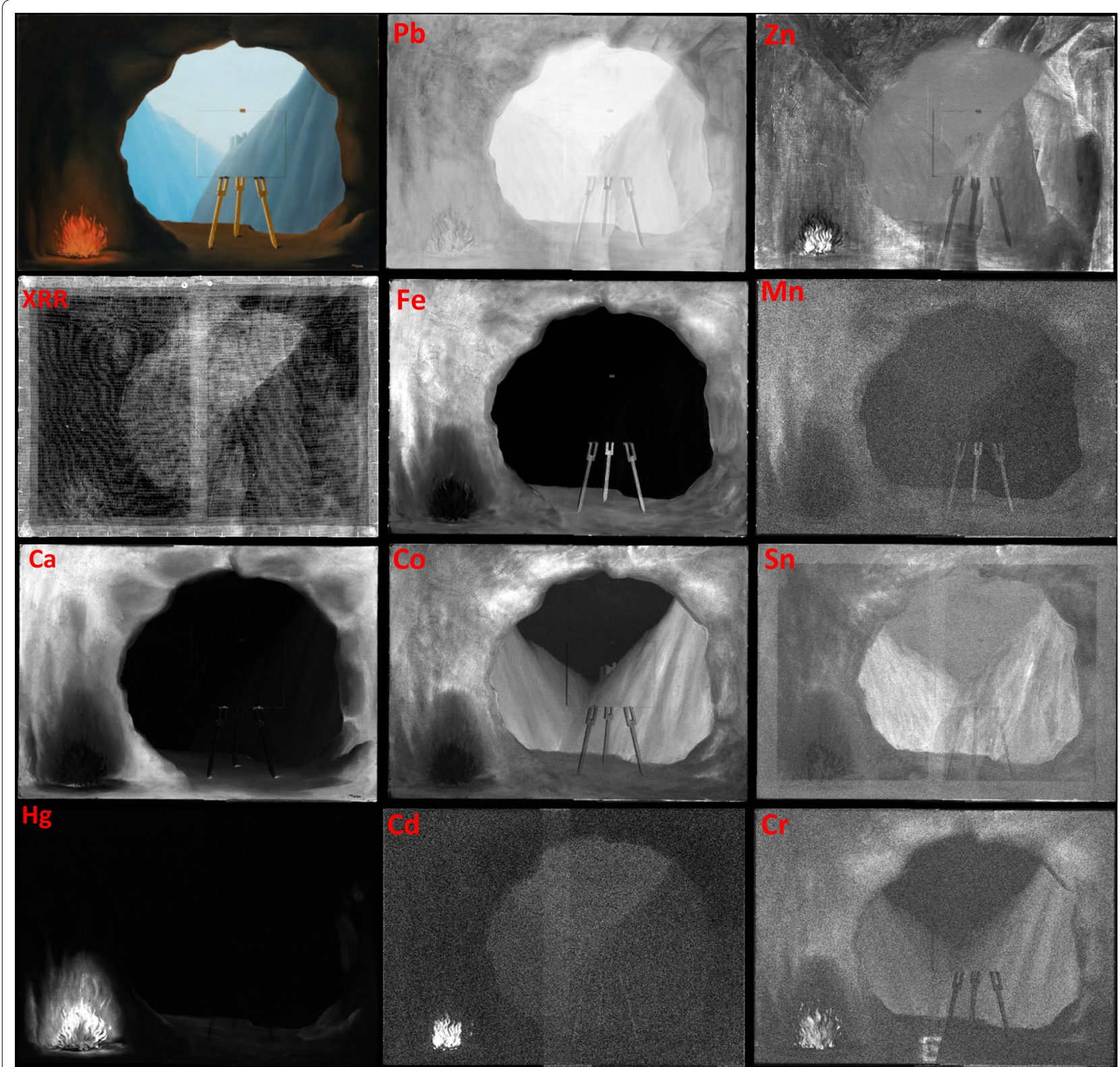

Fig. 5 Normal light image, X-ray radiograph (XRR) and MA-XRF elemental distribution maps detected in La condition humaine; white equals high intensity, black low intensity

bone black [12], both in pure form but also mixed with umber to achieve most of the modelling of the darker browns.

Apart from in the walls of the cave, cobalt (Co) is also present in the blueish mountains paint. The fact that the cobalt signal in the mountains coincides with that of tin $(\mathrm{Sn})$ implies that Magritte used cerulean blue $\left(\mathrm{CoSnO}_{3}\right)$ for the rendering of the mountains and the castle in the distant blueish landscape. The highlights and shadows of the mountain face would have been modelled at this stage.
The sky area displays a noisy signal in the cobalt distribution map, making it difficult to determine if this element is present here. The very light blue tone is painted with a lead white paint to which a small amount of blue pigment was added. Consequently, cobalt might very well be present in a concentration below the detection limit of the MA-XRF instrument, especially when considering the relative low atomic number of this element. However, when examining the data directly (rather that the resulting distributions), the presence of both cobalt and tin are detected at much lower intensities. 
Interestingly, there is also a significant presence of cobalt $(\mathrm{Co})$ and tin $(\mathrm{Sn})$ in the modelling of the cave walls and also of chromium ( $\mathrm{Cr}$ ) but to a lesser extent. The latter element displays a similar distribution to cobalt. Areas rich in cobalt and chromium seems to correspond to areas where the mid/dark browns exhibit a noticeable greenish tint. Iron $(\mathrm{Fe})$, although present mostly due to use of umbers, is also significantly present in these greenish tinted areas, and so it is possible that Magritte used not only umbers and black to model the cave, but also other green and/or blue pigments containing $\mathrm{Cr}$, $\mathrm{Co}$, $\mathrm{Sn}$ and $\mathrm{Fe}$.

The use of chromium oxide green and/or viridian (hydrated chromium oxide) would account for the presence of chromium (Cr). Newman [13] mentions these two types of chromium oxide green, their appearance varying from "a dull opaque olive green to an intense, transparent, somewhat bluish green". There is evidence of a green paint smeared around the edges and onto the reverse of the canvas, including a finger print which we can only assume to be from Magritte's hand (Fig. 6).

This paint varies from a dull opaque green tone as seen on the left edge of the canvas to a more vibrant hue as seen on the finger print to the right edge, suggesting that Magritte was using different greens simultaneously and possibly both types of the chromium oxide.

Alternatively the artist might have resorted to a rarer pigment called 'blue-green chrome'. This pigment with an approximate formula of $\mathrm{Cr}_{2} \mathrm{O}_{3} \cdot \mathrm{CoO} \cdot \mathrm{Al}_{2} \mathrm{O}_{3}$, also mentioned by Newman [13] and Wehlte [14] appears to be made from a fusion of chromium, cobalt and aluminium oxides, and this would explain the presence of $\mathrm{Cr}$ and $\mathrm{Co}$.
An alternative and perhaps a more likely explanation for the co-location of both cobalt ( $\mathrm{Co}$ ) and tin ( $\mathrm{Sn}$ ) could be the use of cerulean blue, then mixed with yellows such as cobalt yellow or an iron (Fe) oxide yellow, and also with chromium $(\mathrm{Cr})$ oxide to achieve a green/blueish colour.

The green paint seen in Fig. 6 is likely to relate to the green used by the artist to modify the browns of the cave, but further analysis with a species-selective analytical technique is needed to enable a full identification of the pigments present (e.g. in situ Raman, FTIR, XRD).

\section{The easel, the canvas, the castle and the fire}

It was only after the modelling of the cave and landscape with its mountains and sky that Magritte began to add the remaining compositional features to the painting. These compositional elements appear to have been added directly without the use of reserves, as illustrated below.

The iron $(\mathrm{Fe})$ map shows clearly that the easel was painted on top of the brown foreground. The composition shows the easel painted in front of and over the foreground. When comparing the painting with the iron distribution map, we can see that the foreground is continuous behind the shapes of the easel legs.

Similarly, when looking at the cobalt (Co) map, we can see that the wooden legs of the easel extend over the blue paint of the mountain. The contours of the depicted canvas, painted with a grey mixture of lead white and bone black, mask the cobalt (Co) and tin ( $\mathrm{Sn}$ ) emissions, showing that these were also painted on top of the mountain blue.

The calcium $(\mathrm{Ca})$ distribution map indicates this element to be abundant in the black paint passages. Here

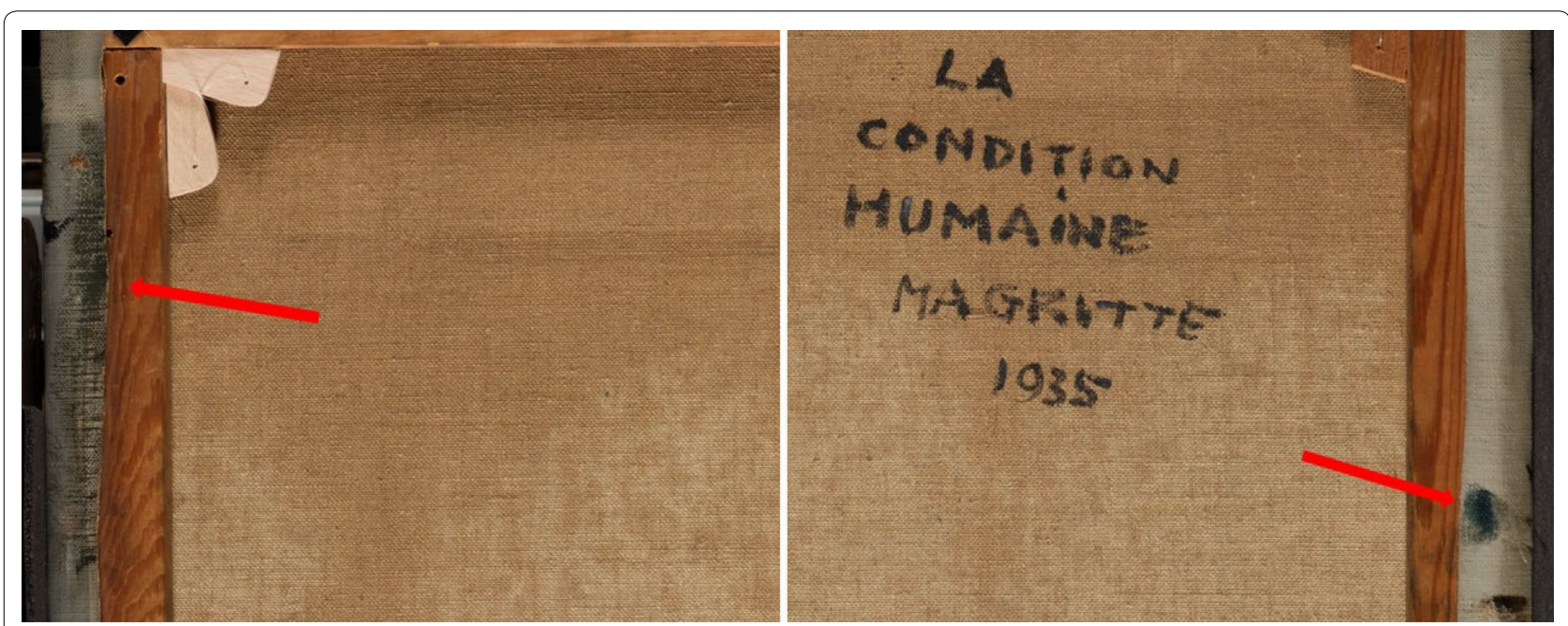

Fig. 6 Details from the reverse of La condition humaine (Fig. 2a): showing olive green paint on the left edge of canvas and a fingerprint in a more translucent green paint on the right edge of the canvas again over the underlying composition. The black inscription is also almost certainly painted by Magritte 
the use of bone black appears in the painting of the fine details of the easel such as the fixings, the nails and the small shadows of the tripod. Calcium can also be detected on all the small tacks along the canvas edge, although here with a much fainter signal.

The castle, presenting a similar elemental distribution of $\mathrm{Co}$ and $\mathrm{Sn}$ and with highlights rich in lead $(\mathrm{Pb})$ as the mountains, was also painted in the same blue (likely cerulean blue) and added after the painting of the sky.

The red/orange fire with its flames and reflections was painted with a large range of different pigments [10]. A mercury $(\mathrm{Hg})$ rich paint, probably vermillion, was used specifically in this area and, apart from a faint thin application to the foreground where the artist thought to convey a warmer tone to the entrance of the cave, it is absent from everywhere else in the composition. It appears to have been applied thinly at first, setting out the position and triangular shape of the warm glow, and probably over the first layer of umber, as the $\mathrm{Hg}$ rich paint seems to shield the iron signal from below (Fig. 5).

Magritte seems to have then progressed by setting out the form of the fire. A pale and cool grey colour containing lead $(\mathrm{Pb})$ was used to establish the centre and the position of the fire in the foreground. At the base of the fire, black $(\mathrm{Ca})$ and dark brown paint $(\mathrm{Fe})$ were used to draw the dark wood/charcoal from which the flames emerges. There is also a pale, opaque yellow layer containing cadmium $(\mathrm{Cd})$ and zinc $(\mathrm{Zn})$, present at the centre and below the intense orange and red fiery flames. This is likely to consist of Cadmium Zinc Sulphide, a yellow/orange pigment $[15,16]$. The deeper red and orange flames were painted with a mixture containing $\mathrm{Hg}, \mathrm{Cr}$ and $\mathrm{Pb}$. The presence of both lead and chromium suggests that a combination of vermillion with chrome yellow was employed to obtain the yellow colour. The varying intensity of the emission signal for mercury $(\mathrm{Hg})$ shows that it was also used in a mixture.

It is possible to also discern a few individual flame details painted with a mid-tone orange, that show specifically both lead $(\mathrm{Pb})$ and chromium $(\mathrm{Cr})$ signals, suggesting the use of chrome orange. Finally there are a few last touches containing iron, likely to have been painted with an iron oxide red $(\mathrm{Fe})$.

\section{La pose enchantée: MA-XRF on the turnover edge}

Elemental imaging (see Fig. 7) was also performed on the turnover edge where the paint of La pose enchantée is exposed, revealing a section of the sky and the wall from this hidden composition (Fig. 7).

The results confirm previous findings and concur with the already established layer build-up (Van der Snickt et al. [9]). The zinc rich ground is covered by a thin priming most probably lead white. The blue sky area is characterized by a strong chromium signal while no other metallic elements such as $\mathrm{Co}, \mathrm{Cu}, \mathrm{Fe}$ or $\mathrm{Sn}$ were detected. This is consistent with the previous proposal that the sky was painted using a blue possibly containing chromium oxide. According to the literature [17], Magritte and others were known to use available and ready mixed blue paints, containing anhydrous chromium (III) oxides to alter the hue of blue pigments. Further analysis as well as sampling from this area would need to be carried out to enable a positive identification of the blue pigment used with a possible addition of a chromium oxide compound, for the rendering of the sky.

Lead white $(\mathrm{Pb})$ was used to model the flesh tones in combination with earth pigments containing iron $(\mathrm{Fe})$ and bone black. Calcium (Ca) was found particularly in

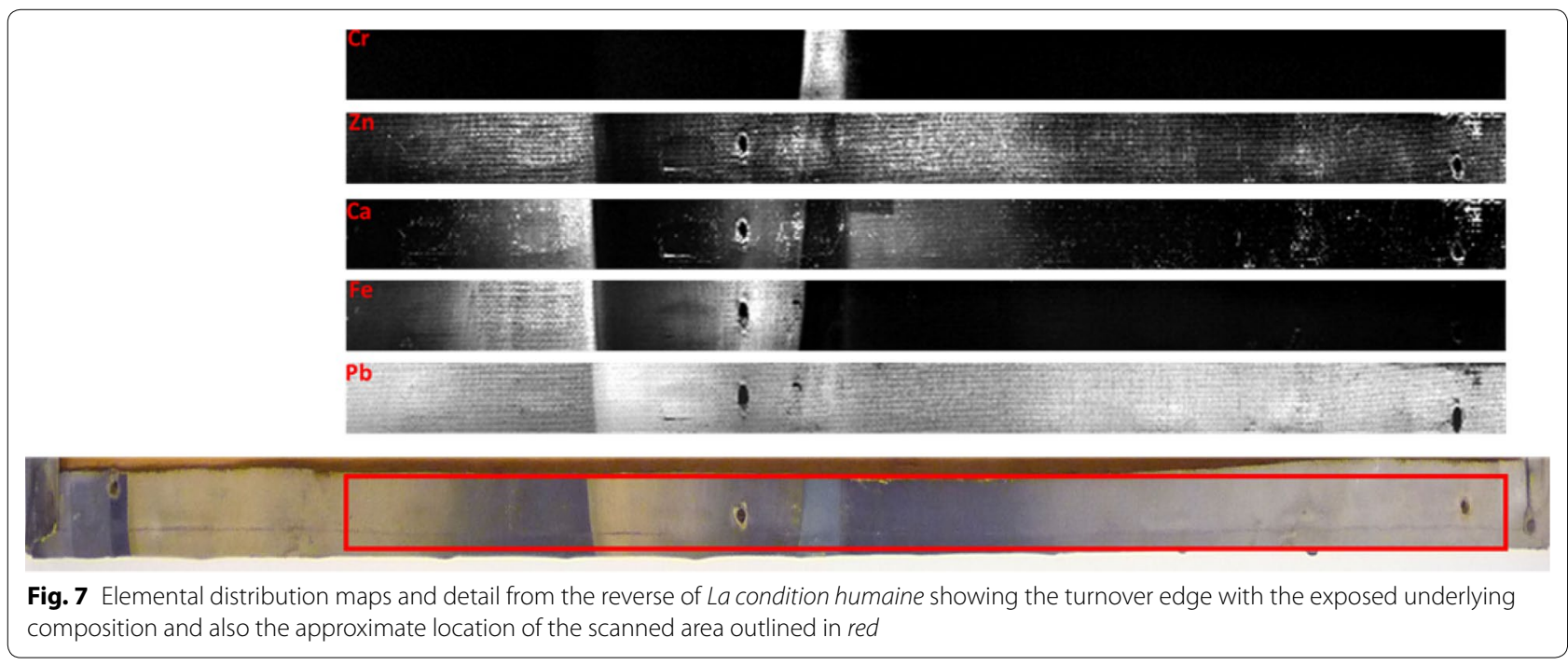


the dark shadows of the flesh tones indicating the use of bone black. The latter was mixed with the warmer earth pigments to achieve the modelling of the standing figure.

In addition, calcium is also found in the shadow that the figure casts on the wall, but no iron is present here. This is a confirmation of what is already visible with the naked eye on this strip of paint, and which makes the most significant addition to our current knowledge of the palette of the underlying painting - that the wall is painted with a simple mixture of lead white and bone black, and is of a cool grey colour. This finding will contribute to the updating of an already proposed colour reconstruction image of Magritte's La pose enchantée [4, 18].

\section{Conclusion}

The elemental identification and mapping of La condition humaine 1935, also containing a section of La pose enchantée, 1927, provided us with further information regarding Magritte's palette during these two distinct periods in his life, at the same time as contributing to a better understanding of the artist's painting technique. His precise paint handling and attention to detail is also demonstrated to be at times intricate and complex as shown for example by the use of a great variety of pigments on a single compositional feature.

This analytical study is a testimony to Magritte's meticulous paint application, resulting in his typical highly defined compositions with contrasting and identifiable elements; this style of painting typical of the artist's oeuvre not compromised at all, even during what must have been in 1935, a very busy and prolific period in his career.

\section{Authors' contributions}

ATDS carried out the initial examination, discovery and conservation treatment on the painting, collaborated on the interpretation of the results and drafted the manuscript. SL carried out the Macro XRF examinations on the painting, carried out the interpretation of these results and contributed to the drafting of the manuscript. GVDS collaborated in the interpretations and contributed to the drafting of the manuscript. RF facilitated and coordinated the XRR and the Macro XRF examinations of the painting. KJ facilitated and coordinated the Macro XRF examination of the painting and contributed useful feedback on the manuscript. GB facilitated the XRR examination of the painting. All authors read and approved the final manuscript.

\section{Author details}

${ }^{1}$ Hamilton Kerr Institute, University of Cambridge, Cambridge CB22 4NE, UK. ${ }^{2}$ Department of Chemistry-AXES Group, University of Antwerp, Groenenborgerlaan 171, 2020 Antwerp, Belgium. ${ }^{3}$ Conservation Studies, University of Antwerp, Blindestraat 9, 2000 Antwerp, Belgium. ${ }^{4}$ Norwich Castle Museum and Art Gallery, Norfolk Museums Service, Norwich NR1 3JQ, UK.

\section{Acknowledgements}

The authors are grateful to Rupert Featherstone [Director, Hamilton Kerr Institute (HKI), University of Cambridge] for organizing and facilitating the macro-XRF scanning and the XRR of the painting at the HKI, to Chris Titmus
(HKI) for producing the XRR image, to Dr. Giorgia Botticelli (curator at Norwich Castle Museum and Art Gallery, Norfolk Museums Service, UK) for her interest and her consent for this study and to Sarah Norcross-Robinson, Man-Yee Liu and Helen Rush (conservation at Norwich Castle Museum- NMS) for their invaluable support during technical examination and conservation treatment.

\section{Competing interests}

The authors declare that they have no competing interests.

\section{Publisher's Note}

Springer Nature remains neutral with regard to jurisdictional claims in published maps and institutional affiliations.

Received: 15 March 2017 Accepted: 25 July 2017

Published online: 29 August 2017

\section{References}

1. Sylvester D, Whitfield S, editors. René Magritte Catalogue Raisonné, vol 2: oil paintings and objects, 1931-1948. Houston: The Menil Foundation, Inc.; 1993.

2. Sylvester $D$, editors. René Magritte Catalogue Raisonné, vol 1: oil paintings 1916-1930. The Menil Foundation, Inc. and P Wilson Publishers, Houston and Amsterdam; 1992.

3. Duffy M, Alberton C, MoMA inside/out blog post, The Discovery of Magritte's La pose enchantée; 2013.

4. Duffy M, Johnson D, MoMA NY, Brava Art Talks 2014, La pose enchantée rediscovered-when a Magritte Hides a Magritte; 2014.

5. Alfeld M, Janssens K, Dik J, de Nolf W, Van der Snickt G. Optimization of mobile macro-XRF systems fort he in situ investigation of historical paintings. J Anal At Spectrom. 2011;26:899.

6. Alfeld M, Janssens K. Strategies for processing mega-pixel X-ray fluorescence hyperspectral data: a case study on a version of Caravaggio's painting Supper at Emmaus. J Anal At Spectrom. 2015:30:777.

7. Solé VA, Papillon E, Cotte M, Walter Ph, Susini J. A multiplatform code for the analysis of energy dispersive $X$-ray fluorescence spectra. Spectrochim Acta Part B. 2007;62:63-8.

8. Brightspec NV/SA, http://www.brightspec.be, Belgium

9. Van der Snickt G, Martins A, Delaney J, Janssens K, Zeibel J, Duffy M, McGlinchey C, Van Driel B, Dik J. Exploring a Hidden Painting Below the surface of René Magritte's Le Portrait. Appl Spectrosc. 2016;70(1):57-67.

10. Gettens R, Stout G. Painting materials, a short encyclopedia. New York: Dover Publications Inc; 1966.

11. Helwig K. Iron oxide pigments: natural and synthetic. In: Berrie BH, editor. Artist's pigments, a handbook of their history and characteristics, vol. 4. Washington: National Gallery of Art; 2007.

12. Vandenabeele P, Verpoort F, Moens L. Non-destructive analysis of paintings using fourier transform Raman spectroscopy with fibre optics. Raman Spectrosc. 2001;32(4):263-9.

13. Newman R. Chromium oxide greens. In: Fitzhugh Elizabeth W, editor. Artist's pigments, a handbook of their history and characteristics, chapter 9 , vol. 3. Washington: National Gallery of Art; 1997.

14. Whelte K. The materials and techniques of painting. Trans. By Ursus Dix. PrenticeHall Press, Simon \& Schuster Inc.; 1975.

15. Laurie AP. The Painter's methods and materials. New York: Dover Publications Inc.; 1967.

16. Patton TC. Pigment handbook, vol. 1. New York: Wiley; 1973.

17. Gautier G, Bezur A, Muir K, Casadio F, Fiedler I. Chemical fingerprinting of ready-mixed house paints of relevance to artistic production in the first half of the twentieth century. Part I: inorganic and organic pigments. Appl Spectrosc. 2009;63(6):597-603.

18. Martins A, McGlinchey C, Duffy M. MoMA inside/out blog post, Magritte's La pose enchantée, 1927: Palette Inveiled; 2013. 